\title{
NOMES NUS NA AQUISIÇÃO E NO PROCESSAMENTO ADULTO
}

Davidson dos Santos é graduando em Letras com ênfase em Linguística pela Universidade Federal de Juiz de Fora 1

\section{Resumo}

O trabalho explora o fenômeno do nome nu singular no $\mathrm{PB}$, quando combinado com predicados episódicos e de espécie, numa perspectiva psicolinguística. Resultados de um experimento de leitura automonitorada sugerem que DPs são avaliados mais rapidamente do que NPs e que sentenças contendo nomes nus não são julgadas de forma categórica pelos falantes. Os resultados não permitem afirmar que o nome nu singular é aceito com os predicados investigados.

\begin{abstract}
This paper explores singular bare nouns combined or with predicates of kind or episodic in Brazilian Portuguese in a psycholinguistic perspective. Results of an experiment with self-paced reading suggest that DPs are evaluated faster than NPs and that speakers do not judge categorically sentences containing bare nouns. The results do not allow affirming that singular bare nouns are well accepted when combined with the investigated predicates.
\end{abstract}

\section{1) Introdução}

A expressão linguística de noções como "número" e "quantidade" pode ser feita por elementos que veiculam quantificação aproximada (quantificadores universais, indefinidos e outras expressões quantificadas), itens lexicais que remetem a quantidades exatas (numerais) e/ou símbolos explícitos (morfemas ou partículas) que estabelecem o contraste entre singular/plural. No entanto, certas estruturas parecem desafiar a afirmação anterior. Esse é, por exemplo, o caso dos chamados nomes nus, cuja interpretação pode não corresponder estritamente a uma leitura singular ou plural.

De acordo com Pires de Oliveira (2012), não há uma única caracterização para os denominados nominais nus em virtude da existência de variados sistemas de sintagmas nominais presentes nas línguas naturais e, ainda, pela existência de diferentes teorias para explicar a sintaxe e a semântica desses sintagmas. No entanto, apesar das divergências na caracterização desse fenômeno, há consenso entre as diversas propostas teóricas em reconhecer que as expressões em itálico nos exemplos a seguir são nomes nus:

(1) Lagartixa é um bicho nojento.

(2) Cachorro late.

(3) Vi filme ontem a tarde inteira.

(4) Mulheres choram à toa.

(5) Comprei laranjas na feira.

As expressões sublinhadas são consideras como nominais nus, uma vez que não há determinante (D) foneticamente realizado, podendo apresentar morfologia de número

\footnotetext{
1 A pesquisa reportada no presente artigo foi desenvolvida no âmbito de uma Bolsa de Iniciação Científica (BIC/UFJF) vinculada ao projeto Processamento de expressões quantificadas: explorando a relação entre língua e cognição numérica coordenado pela Profa. Mercedes Marcilese. O referido projeto, conta com aprovação do Comité de Ética em Pesquisa da instituição (CAAE: 26747214.6.0000.5147).
} 
plural (4 e 5) ou traço zero no que tange a essa característica (1, 2 e 3$)$ e ocupar posição de argumento interno ou externo.

Diferentemente de outras línguas românicas, como o francês, o italiano e o espanhol, que apresentam o nominal nu plural, no Português Brasileiro (PB) o nome nu singular também é muito produtivo, como se verifica nos exemplos supracitados. Expressões contendo nomes nus singulares PB - ilustradas em (6) e (7) com exemplos retirados de Pires de Oliveira (2012) - constituem um tópico de investigação bastante relevante nesse sentido. Embora, superficialmente, tais expressões estejam codificadas no singular, a interpretação atribuída a esse tipo de sintagma é alvo de controvérsia na literatura especializada.

(6) Lagartixa é um bicho nojento.

(7) Vi filme ontem a tarde inteira.

No que diz respeito à aquisição de nominais nus, aparentemente, por não haver no PB diferentes padrões morfológicos que restrinjam a possibilidade de leitura genérica dos nomes nus - como acontece em línguas como o inglês, as crianças teriam uma maior dificuldade para a interpretação desse tipo de sintagma. Em outras palavras, a ausência de $\mathrm{D}$ e de marcas de pluralidade são fatores de relevância no que tange à possibilidade de atribuir uma leitura genérica ou específica, sendo a primeira mais abrangente que a segunda (Augusto, 2007). Dados experimentais obtidos com crianças e com um grupo controle formado por adultos, sugerem que o nome nu começa a ser interpretado de forma mais próxima da "leitura adulta", apenas após dos 3 anos de idade (Augusto, 2007).

Especificamente no caso do presente artigo, o trabalho de Pires de Oliveira, Silva \& Bressane (2010) foi tomado como ponto de partida para nossa investigação. Esse estudo buscou verificar a aceitabilidade/gramaticalidade do singular nu (doravante, $\mathrm{SNu}$ ) em sentenças episódicas e de espécie. Na nossa pesquisa, buscamos aprofundar o debate no que tange aos $\mathrm{SNu}$, levando em conta aspectos não explorados ou claramente delimitados pelo estudo supracitado.

Para melhor entendimento do leitor, o presente artigo está organizado nas seguintes seções: caracterização do singular nu, breve discussão das divergências teóricas encontradas na literatura no que tange à descrição desse fenômeno, apresentação da metodologia empregada, descrição e resultados do experimento conduzido, considerações finais.

\section{2) O Nome Nu Singular no PB}

Como vimos, não há uma única caracterização para os denominados nominais nus. Enquanto em outras línguas românicas é possível encontrar nomes nus plurais, o PB apresenta ainda ocorrências de nominais nus singulares. Há ainda línguas como o inglês, por exemplo, que licenciam seu uso no singular quando se trata de nu de massa como em (8), mas não quando se trata de um nome nu contável como em (1), (2) e (3): 
(8) Milk is healthy.

'Leite é saudável'.

Em inglês, não há o licenciamento de nomes de massa singulares com $\mathrm{D}$ definido e leitura genérica - como em (9) -, mas em expressões com valor genérico ocorre o nome nu como vimos em (8) acima (Pires de Oliveira, 2012):

(9) *The milk is healthy.

No sentido de clarificar o fenômeno linguístico escolhido como alvo de estudo na nossa pesquisa, valemo-nos das sentenças abaixo retiradas de Müller (2003):

(10) Brasileiro é trabalhador.

(11) Dinossauro está extinto.

Sentenças como (10) e (11), nas quais o sujeito (brasileiro e dinossauro) não está acompanhado de um $\mathrm{D}$, são muito produtivas no $\mathrm{PB}$, podendo essas apresentar leitura genérica $=$ todo brasileiro é trabalhador $\mathrm{e}=$ todo dinossauro está extinto. Em ambos os casos, temos um $\mathrm{SNu}$ singular, que pode ser caracterizado como um sintagma nominal o qual, foneticamente, é desprovido de D:

O singular nu é caracterizado por ser um sintagma nominal - em sentido amplo, isto é um sintagma cujo núcleo é um nome - sem um determinante aparente, sendo constituído, portanto, apenas pelo nome. (PIRES DE OLIVEIRA, SILVA \& BRESSANE, 2010, p. 117).

Essa discussão torna-se mais instigante quando debruçamos nosso olhar para sentenças como (12) e (13):

(12) Homem joga futebol.

(13) Automóvel chegou ao Brasil.

Nota-se que, assim como em (10) e (11), a mesma leitura genérica pode ser realizada com a sentença (12). Entretanto, em (13) parece haver um esforço maior para acomodarmos a mesma leitura. Observando as sentenças (12) e (13), percebemos que são de naturezas distintas: enquanto a primeira é do tipo episódica, a segunda é envolve um predicado de espécie. Entende-se como sentença episódica aquela em que o predicador expressa episódios específicos ou fatos isolados. Krifka et al. (1995) apud Mezari (2011:15) caracterizam predicados episódicos como aqueles "que expressam afirmações sobre eventos particulares, propriedades de objetos particulares, e assim por diante". 
Já as sentenças de espécie ${ }^{2}$ são entendidas como as que caracterizam uma espécie, ou seja, que não designam indivíduos particulares, mas fazem referência à espécie, como explica Mezari (2011:14):

Um indivíduo comum, ordinário - João, por exemplo -, portanto, só pode estar em um lugar em um tempo definido. Uma espécie - baleia, por exemplo -, por outro lado, está presente em vários lugares, diferentes, em um momento dado do tempo, já que, tratando-se da espécie, há vários espécimes.

Bessaydes (no prelo, apud Mezari, 2011) considera o fato de espécies serem espacialmente descontínuas como a propriedade que diferencia crucialmente indivíduos ordinários de espécies. Em outras palavras, indivíduos podem ser identificados a partir das suas coordenadas espaço-temporais, enquanto que uma mesma espécie pode ocupar vários espaços ao mesmo tempo.

Com a finalidade de exemplificar a diferença entre sentenças episódicas e de espécie, consideraremos um dos testes apresentados por Krifka apud Mezari (2011), no qual a inserção do advérbio sentencial "geralmente" torna a sentença episódica estranha ou agramatical (15.b), mas não altera o significado da sentença espécie (14.b):

(14) a. O brasileiro é persistente ${ }^{3}$.

b. O brasileiro geralmente é persistente.

(15) a. O irlandês acaba de desembarcar no aeroporto de Florianópolis.

b. *O irlandês geralmente acaba de desembarcar no aeroporto de Florianópolis.

Na comparação entre a (14a) e (14b), nota-se que não há grandes diferenças no significado das sentenças. Entretanto, não é o mesmo que ocorre em (15), já que o acréscimo do advérbio torna (15b) uma sentença agramatical no PB. Sendo assim, temse (14) como uma sentença que denota espécie e (15) como episódica.

Tal explanação acerca da natureza desses dois tipos de sentenças - episódicas ou particularizadas vs. de espécie - é relevante para o nosso trabalho, haja vista que, na literatura, há divergências quanto à aceitabilidade do nominal nu em sentenças com predicados episódicos e de espécie. Sendo assim, buscaremos, através da utilização de metodologia experimental, contribuir com as discussões acerca da interpretação do $\mathrm{SNu}$ no PB. Nesse sentido, na seção seguinte, apresentaremos um breve panorama referente às discussões teóricas travadas acerca do $\mathrm{SNu}$ no $\mathrm{PB}$ e suas possíveis interpretações.

\footnotetext{
2 Um segundo tipo de sentenças com interpretação genérica são as denominadas sentenças caracterizadoras, que englobam sentenças genéricas disposicionais, habituais, dentre outros tipos. Mezari (2011) destaca que as sentenças caracterizadoras contrastam com as sentenças particularizadas ou episódicas, pelo fato de não expressarem afirmações sobre eventos particulares ou propriedades de objetos particulares e não se localizarem espaço-temporalmente. Esse tipo de expressão de genericidade foge ao escopo do presente trabalho, mas mencionamos essas estruturas pelo fato de que - assim como as sentenças de espécie - elas opõem-se às sentenças particularizadas ou episódicas.
}

\footnotetext{
${ }^{3}$ Exemplos retirados de Mezari (2011).
} 


\section{1) Divergências teóricas na caracterização dos singulares nus no PB}

Como vimos, diferentemente de outras línguas românicas, o PB tem o nominal singular nu como muito produtivo, quando em posição de sujeito. Entretanto, a literatura diverge no tocante a sua interpretação genérica em sentenças episódicas e de espécie.

Dentre o que nos apresenta a literatura, discorreremos sobre as três propostas teóricas acerca da questão da aceitabilidade do $\mathrm{SNu}$ em sentenças episódicas e de espécie, quais sejam: (i) Müller (2003), que argumenta que o nominal singular nu em sentenças de espécie seria agramatical (de acordo com a autora, a sentença em (11), * Dinossauro está extinto, seria malformada no $\mathrm{PB}$ ), bem como a possibilidade do $\mathrm{SNu}$ se combinar com predicado episódico, gerando uma interpretação genérica (*Automóvel chegou ao Brasil no século XX); (ii) por sua vez, Schmitt \& Munn (1999) apud Mariano (2011) e (iii) Pires de Oliveira \& Rothstein $(2011$; 2012), que consideram que há o licenciamento do singular nu em sentenças desses tipos sob certas condições específicas. Tal discordância dá-se devido à natureza atribuída ao nominal nu em cada caso. Müller (2003) defende que o nominal nu, na verdade, é um tópico da sentença e não o sujeito e nem o argumento externo do verbo (i.e. um predicado do tipo $<\mathrm{e}, \mathrm{t}>$ ), sendo, então, um NP e não um DP, como observamos nos exemplos retirados de Mariano (2011):

(16) Menina brinca de carrinho.

Nos termos de Müller (2003), a sentença em (16) significa que "em geral, se algo é menina, esse algo brinca de boneca". Em outras palavras, o nominal nu encontrase em posição de tópico sentencial, podendo apresentar somente uma leitura genérica, já que assume uma posição acima de TP. Dessa maneira, sentenças como em (17), são entendidas como agramaticais, pois não é possível atribuir leitura genérica ao sintagma nominal "menino" (MÜLLER, 2002):

(17) *Menino está com fome.

Em (17) não há possibilidade da leitura: "geralmente, se algo é menino, esse algo está com fome", o que levaria a agramaticalidade da sentença.

Diferentemente de Müller (2003), Schmitt \& Munn (1999) apud Mariano (2011) defendem que o nominal singular nu é gramatical no PB, podendo assumir as posições de sujeito e de objeto na sentença. Entretanto, em sentenças episódicas, como em (17), sua ocorrência como sujeito apresentaria restrições. Em outras palavras, é necessário haver uma situação de focalização para que a sentença seja marcada em PB, como apresentamos nos exemplos retirados de Mariano (2011):

(18) MULHER discutiu as eleições.

(19) Só mulher discutiu as eleições,

(20) Mulher discutiu as eleições, homem discutiu futebol. 
Em (18) a focalização dá-se por foco prosódico, em (19) pelo item focalizador só e em (20) pelo contexto contrastivo.

Pires de Oliveira e Rothstein (2011) apud Mariano (2011), por sua vez, defendem que o $\mathrm{SNu}$ denota sempre espécie, havendo mudança de tipo semântico (type shifting), já que o nominal nu é gerado por uma operação na qual "o operador Down seleciona um predicado e devolve um indivíduo". Assim, sentenças como em (21) são compreendidas como gramaticais:

\section{(21) João comeu maçã.}

Na sentença (21) temos que o indivíduo João comeu um item da espécie maçã, havendo, assim, uma interação entre os itens em destaque. A sentença para os autores é entendida como verdadeira, pois "maçã" representará um item saliente de toda a espécie.

A seguir, resenharemos brevemente o trabalho de Pires de Oliveira, Silva \& Bressane (2010), que tomamos como ponto de partida para nossa pesquisa experimental.

\section{2) Pires de Oliveira, Silva \& Bressane (2010)}

O trabalho de Pires de Oliveira, Silva \& Bressane (2010) retoma a discussão, no que tange à interpretação do $\mathrm{SNu}$ singular, neste caso, lançando mão de metodologia vinculada à denominada Semântica Experimental. Os autores discutem as duas análises principais, previamente mencionadas: enquanto Müller (2003) rejeita a possibilidade de o nu singular denotar espécie, Schmitt \& Munn (1999) apud Mariano (2011) e Pires de Oliveira e colaboradores consideram que essa seria uma opção válida em determinados contextos no PB.

A fim de obter evidências compatíveis com a ideia de que SNus poderiam se combinar com predicados de espécie, os autores optaram por partir da análise de dados naturalistas e realizaram uma busca de ocorrências desse tipo em bancos de dados de língua falada (Nurc e Varsal) e escrita (busca no Google, considerando principalmente blogs). Essa busca centrou-se em predicados que são, segundo a literatura, indiscutivelmente, de espécie (Ex. acabar, extinguir e desaparecer), em todas as suas formas modo-temporais. Apesar da pequena quantidade de dados encontrados (23 ocorrências nos dados de fala, sendo que em apenas um caso o $\mathrm{SNu}$ ocupava a posição de sujeito e alguns poucos registros nos dados escritos), a presença - embora escassa de $\mathrm{SNu}$ singulares com predicados de espécie é utilizada, pelos autores, como argumento da legitimidade de tais estruturas no PB. De acordo com os autores, sentenças agramaticais seriam aquelas que não podem ser produzidas por um falante nativo da língua. Nesse sentido, o aparecimento das estruturas investigadas no corpora avaliado atestaria a gramaticalidade das mesmas. Um ponto levantando pelos autores relaciona-se ao entendimento do próprio conceito de "espécie" (kind), pelo fato de não 
haver na literatura um aprofundamento teórico claro sobre essa nomenclatura, o que permitiria enquadrar muitos itens potencialmente distintos dentro dessa única categoria.

A fim de melhor explorar o fenômeno do $\mathrm{SNu}$ no $\mathrm{PB}$, os autores conduziram uma atividade experimental, cujo objetivo foi verificar a aceitabilidade/gramaticalidade dessa estrutura por falantes da língua. Para tal, foram elaboradas 36 sentenças das quais 24 experimentais e 12 distratoras - cada qual formada por uma matriz e uma encaixada, ocorrendo na última as estruturas a serem investigadas. As sentenças foram organizadas de acordo com quatro condições experimentais:

i) Singular nu + predicado de espécie: $O$ Carlos disse que $\varnothing$ batata é rara nessa região;

ii) Definido singular + predicado de espécie: O Carlos disse que a batata é rara nessa região;

iii) Singular nu + predicado episódico: O João disse que $\varnothing$ café chegou no Brasil em 1990; e

iv) Definido singular + predicado episódico: O João disse que o café chegou no Brasil em 1990.

Desse experimento participaram 200 sujeitos, todos com nível universitário, oriundos de Santa Catarina, divididos nas quatro condições experimentais. Isto é, cada participante foi apresentado para apenas uma das condições (ou seja, o design experimental não seguiu a estrutura de quadrado latino já que cada item não tinha uma versão em cada uma das quatro condições experimentais).

A tarefa experimental utilizada foi um julgamento de aceitabilidade por meio de um questionário off-line, no qual foi utilizada uma escala não numérica que reproduzimos a seguir:

(20) Ex. O João leu que dinossauro foi extinto por um cometa. (:). :

(a separação entre os dois extremos da escala foi de $10 \mathrm{~cm}$ )

Aos participantes foi dado o comando para que lessem apenas uma vez cada sentença e, imediatamente, assinalassem o grau de aceitabilidade da sentença, levando em conta a escala anteriormente ilustrada.

$\mathrm{Na}$ análise dos resultados, os julgamentos foram organizados da seguinte forma: julgamentos que marcaram o rosto sorridente ou próximo a ele recebiam nota 100,50 para os julgamentos marcados na zona intermediária e zero para o rosto triste e suas proximidades, como reproduzimos a seguir:

;). 100 .50 0 :

Os autores reportam que, as sentenças gramaticais - utilizadas como distratoras, Ex. O João viu o filme - tiveram um alto índice de aceitação, enquanto as agramaticais 
(também distratoras, por ex. O Carlos disse que o quadro pintou) não foram bem avaliadas. As respostas fornecidas pelos participantes para as sentenças distratoras (gramaticais e agramaticais, segundo classificação dos próprios autores) foram tomadas como referência para avaliar os julgamentos atribuídos às sentenças experimentais. Entretanto, não é discutido no decorrer do estudo o que se está sendo exatamente classificado como gramatical e agramatical, e as sentenças caracterizadas como "agramaticais" apresentam uma variação importante entre si, incluindo ainda exemplos que contém SNus (Comparar por exemplo: O Pedro leu que o sapato ficou caro e $A$ Márcia viu que sapato estragou). Além desses problemas, os resultados obtidos não foram submetidos a tratamento estatístico e o trabalho sofre de outras fraquezas derivadas da ausência de controle dos standards usuais no trabalho experimental nas ciências cognitivas.

Possivelmente em decorrência da falta de controle de vários aspectos metodológicos, os resultados obtidos - apesar do grande número de sujeitos avaliados não se mostram compatíveis nem com a aceitação e nem com a rejeição das sentenças com nominais singulares nus com leitura genérica quando em sentenças de espécie ou com predicados episódicos. O comportamento dos participantes parece ter ficado no nível da chance, sugerindo um julgamento não categórico das estruturas testadas.

Com a finalidade de contribuir para essa discussão, e entendendo que o experimento apresentado por Pires de Oliveira, Silva \& Bressane (2010) apresenta as limitações anteriormente mencionadas, optamos por replicar o teste original, mas introduzindo algumas alterações que, julgamos, permitiriam explorar o fenômeno em questão de uma forma mais controlada. Na próxima seção, descreveremos $\mathrm{o}$ experimento conduzido por nós a partir dos estímulos construídos por Pires de Oliveira, Silva \& Bressane (2010).

\section{3) Julgamento de SNu com predicados episódicos e de espécie}

Nesse estudo, utilizamo-nos da metodologia experimental nos moldes propostos no campo da psicolinguística, cujo objetivo é a descrição e análise do modo como o ser humano adquire, compreende, e produz linguagem. A psicolinguística experimental busca investigar o processamento linguístico, salientando o fato de que o mesmo ocorre na mente humana. Para tal, são idealizadas atividades experimentais adequadas para o tipo de fenômeno a ser analisado e/ou o objeto focalizado em cada caso, e que pode darse em diferentes níveis gramaticais (fonológico, morfológico, sintático, semântico).

\section{1) Descrição do experimento conduzido}

\section{Design experimental}

Nosso experimento teve como ponto de partida a atividade idealizada por Pires de Oliveira, Silva \& Bressane (2010), cujo objetivo foi a verificação da aceitabilidade/gramaticalidade do nominal singular nu por falantes do PB quando combinado com predicados episódicos e de espécie. No entanto, como apontamos anteriormente, o experimento original apresentava algumas falhas metodológicas, o que 
nos levou a replicá-lo, procurando - na medida do possível - superar algumas das restrições iniciais.

Primeiramente, mantivemos as mesmas sentenças e preservamos o design original do experimento de Pires de Oliveira, Silva \& Bressane (2010), explicitando o mesmo de acordo com as convenções da metodologia experimental no campo da psicolinguística. Assim, as variáveis independentes foram: tipo de sintagma (NP - no caso do $\mathrm{SNu} / \mathrm{DP}$ ) e tipo de predicado (episódico/de espécie), sendo ambos fatores between subjects. A combinação dessas variáveis (design 2X2) deu como resultado as quatro condições experimentais anteriormente descritas e reiteradas a seguir:

i) NP + predicado de espécie;

ii) $\mathrm{DP}+$ predicado de espécie;

iii) NP + predicado episódico; e

iv) DP + predicado episódico.

Diferentemente do experimento original, que empregou um questionário off-line, optamos por uma tarefa de julgamento mais rápida e controlada que possibilitasse a inserção de uma segunda variável dependente - além do número de julgamentos positivos e negativos considerados na pesquisa original. Por meio de uma tarefa semicontrolada de julgamento de sentenças, foi adicionada a variável dependente tempo de julgamento. Para tal, utilizamo-nos do programa DMDX, por acreditarmos ser uma ferramenta que atenderia a finalidade da pesquisa, qual seja, a verificação do processamento das sentenças, através da técnica de leitura monitorada, que nos permite mensurar o tempo de leitura/julgamento e a resposta do participante em relação a sentença alvo. Assim, buscamos verificar o julgamento dos participantes em relação as duas variáveis independentes: tipo de sintagma (NP, DP) e tipo de predicado (episódico, de espécie) considerando as seguintes variáveis dependentes: tempo de julgamento (envolvendo os tempos relativos à leitura + julgamento) e tipo de julgamento (caracterizados nominalmente como bom, não sei e ruim). Não foi possível medir separadamente os tempos de leitura e julgamento pelo fato das sentenças não comportarem o mesmo número de sílabas, o que inviabiliza a comparação dos tempos de leitura nas distintas condições e até mesmo no interior de uma única condição. Cabe lembrar que optamos por utilizar as mesmas sentenças do experimento original, motivo pelo qual não foi possível introduzir as mudanças necessárias para que todos os estímulos fossem comparáveis em termos de tempo de leitura. Por esses motivos, decidimos realizar uma tarefa de leitura automonitorada de frases completas e registrar o tempo de julgamento imediatamente após a leitura.

\section{Participantes}

Participaram do experimento 20 voluntários, sendo todos eles estudantes universitários de diferentes cursos da Universidade Federal de Juiz de Fora, dentre os quais 11 homens e 9 mulheres, todos com idade entre 18 e 25 anos. Pelo fato de utilizarmos os estímulos construídos por Pires de Oliveira, Silva \& Bressane (2010) que não comportavam uma estrutura de quadrado latino - da mesma forma que no 
experimento original, cada participante teve acesso apenas a uma das condições experimentais investigadas, ou seja, o participante que respondia à lista com sentenças episódicas com DP, por exemplo, não avaliou nenhum outro tipo de sentenças.

\section{Materiais e procedimento}

Como já informado, foram utilizadas as sentenças originais, tal e como idealizadas por Pires de Oliveira, Silva \& Bressane (2010). Além dos estímulos experimentais (6 por condição), foram utilizadas 12 sentenças distratoras, também calcadas no estudo original. Para a execução do teste, utilizamo-nos de um computador com o software DMDX. Levando em conta a lógica do programa, foram inseridas as sentenças codificadas e as tarefas a serem executadas: primeiramente, instruções sobre o experimento e sua execução. Depois, para que os participantes se familiarizassem com o procedimento, foi incluído um pequeno "pré-teste" com sentenças nos mesmos moldes do experimento em si e, terminada essa etapa, o participante iniciava, de fato, o experimento. Aparecia, então, uma sentença na tela. Para seguir com a tarefa, o participante deveria ler a sentença, avançar para uma segunda tela e julgar a sentença escolhendo uma dentre as três opções apresentadas - como "boa", "não sei" ou "ruim". Para realizar o julgamento, o participante devia apertar uma das três teclas destacadas no teclado do computador.

É importante reforçar que, em termos procedimentais, o experimento se difere do conduzido por Pires de Oliveira, Silva \& Bressane (2010), haja vista que na versão adaptada por nós: (i) restringimos o tempo disponível para a leitura das sentenças na tela do computador e, neste caso, em vista da oscilação de tamanho dos estímulos anteriormente apontada, esse tempo foi ajustado de acordo com o tamanho de cada item; (iii) limitamos o tempo disponível para o julgamento da sentença, não sendo possível ao participante retornar à sentença anterior; (ii) registramos para posterior análise o tempo de julgamento das sentenças (leitura + julgamento); (iv) modificamos a escala de julgamento, sendo possível escolher entre "bom", "não sei" e "ruim". Todas essas modificações visavam a:

(a) Favorecer respostas mais automáticas e, portanto, mais compatíveis com um julgamento intuitivo de aceitabilidade por parte dos participantes;

(b) Pré-estabelecer um critério mais objetivo que orientasse e facilitasse a tabulação e análise dos dados, de maneira que foram estabelecidas três possíveis respostas nominais ("bom", "não sei” e "ruim"), claramente delimitadas, no lugar de um continuum como no caso da escala originalmente utilizada por Pires de Oliveira, Silva \& Bressane (2010).

$\mathrm{O}$ experimento visou verificar em que medida os falantes do PB julgam como aceitáveis sentenças com predicados episódicos e de espécie com nomes singulares nu. Em virtude das discussões levantadas na literatura e anteriormente resenhadas, uma aceitação significativa desse tipo de sentenças traria evidências compatíveis com a ideia, defendida por Pires de Oliveira, Silva \& Bressane (2010), de que os falantes atribuem uma leitura genérica aos nomes singulares nus, quando em contextos particulares (i.e. 
quando combinados com predicados episódicos). Ao mesmo tempo, um resultado que sugerisse uma aceitação da combinação nome singular nu + sentença de espécie desafiaria a afirmação de Müller (2002) de que este tipo de sentenças seria agramatical no PB.

\section{2) Resultados}

Os resultados relativos aos tempos de julgamento de cada sentença foram submetidos a uma análise da variância por item, com design fatorial $2 \mathrm{X} 2$ (tipo de sintagma, tipo de predicado). Nessa análise não foram obtidos efeitos estatisticamente significativos, provavelmente devido ao tamanho reduzido da amostra. No entanto, uma comparação entre pares (teste t-student), contrastando os tempos de julgamento das sentenças com e sem determinante - independentemente do tipo de predicador envolvido - aproximou-se do nível de significância $(\mathrm{t}(19)=1.65 \mathrm{p}=0.06$ ) (Médias de 3100 milissegundos para o julgamento das condições com determinante e 3540 milissegundos para os trials sem determinante). Esse resultado sugere que, de modo geral, sentenças com determinante seriam mais rapidamente julgadas quando comparadas com sentenças com nomes nus singulares (cf. o Gráfico 1 a seguir).

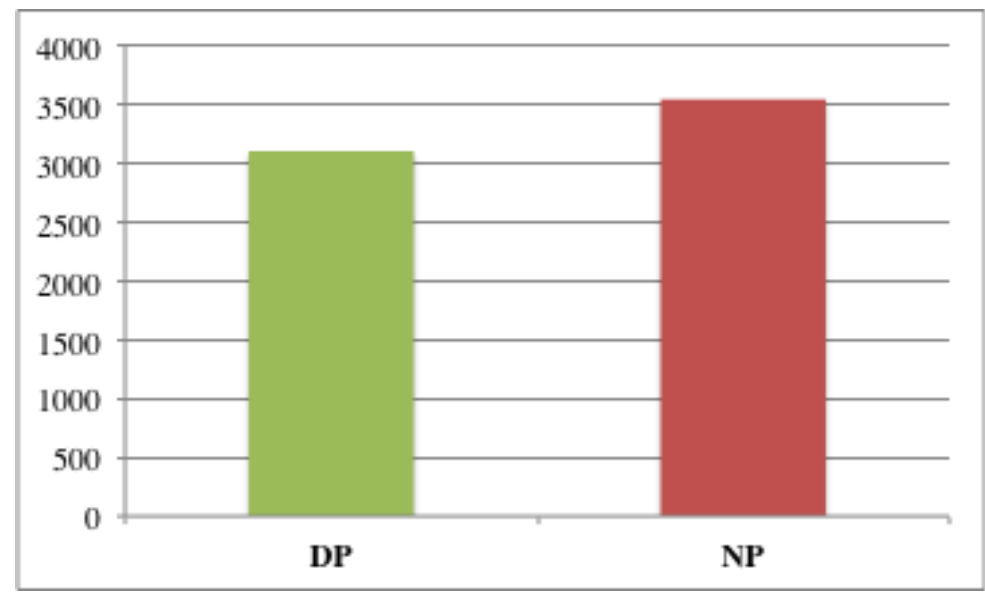

Gráfico 1: Tempo de resposta em milissegundos em função de tipo de sintagma.

No que tange ao julgamento das sentenças em cada condição, devido ao tamanho atualmente reduzido da nossa amostra (20 participantes no total), e o número ainda menor de participantes por condição ( 5 por condição), não foi possível a aplicação de testes de inferência estatística ${ }^{4}$. Por esse motivo, optamos por realizar aqui uma análise - reconhecidamente preliminar e qualitativa - considerando apenas os percentuais

\footnotetext{
${ }^{4}$ Entendemos que, como bem apontou um parecerista anônimo ao avaliar o presente artigo, a ausência de tratamento estatístico no que tange a essa variável dependente, constitui um ponto fraco do nosso trabalho. No entanto, vale salientar que no trabalho que inspirou o nosso experimento foi avaliado um número expressivo de participantes (200 no total) e que, guardadas as devidas proporções, nossos resultados são compatíveis com o encontrado naquela amostra. Uma futura ampliação da nossa amostra viabilizará a condução de testes estatísticos que permitam extrair generalizações a partir dos resultados obtidos.
} 
relativos aos tipos de julgamento atribuídos em cada caso (lembrando que as opções de julgamento disponibilizadas no teste foram bom/não sei/ruim). Os resultados obtidos até então não se mostram compatíveis com uma aceitação irrestrita das sentenças contendo nomes nus. De fato, apesar do tamanho reduzido da nossa amostra, os resultados relativos à variável dependente julgamentos positivos estão na mesma direção do reportado por Pires de Oliveira, Silva \& Bressane (2010). Nesse sentido, como pode ser observado nos gráficos a seguir, o percentual de rejeição das sentenças episódicas e de espécie com $\mathrm{SNu}$ é relativamente alto quando comparado com o mesmo tipo de predicador, porém com DP.

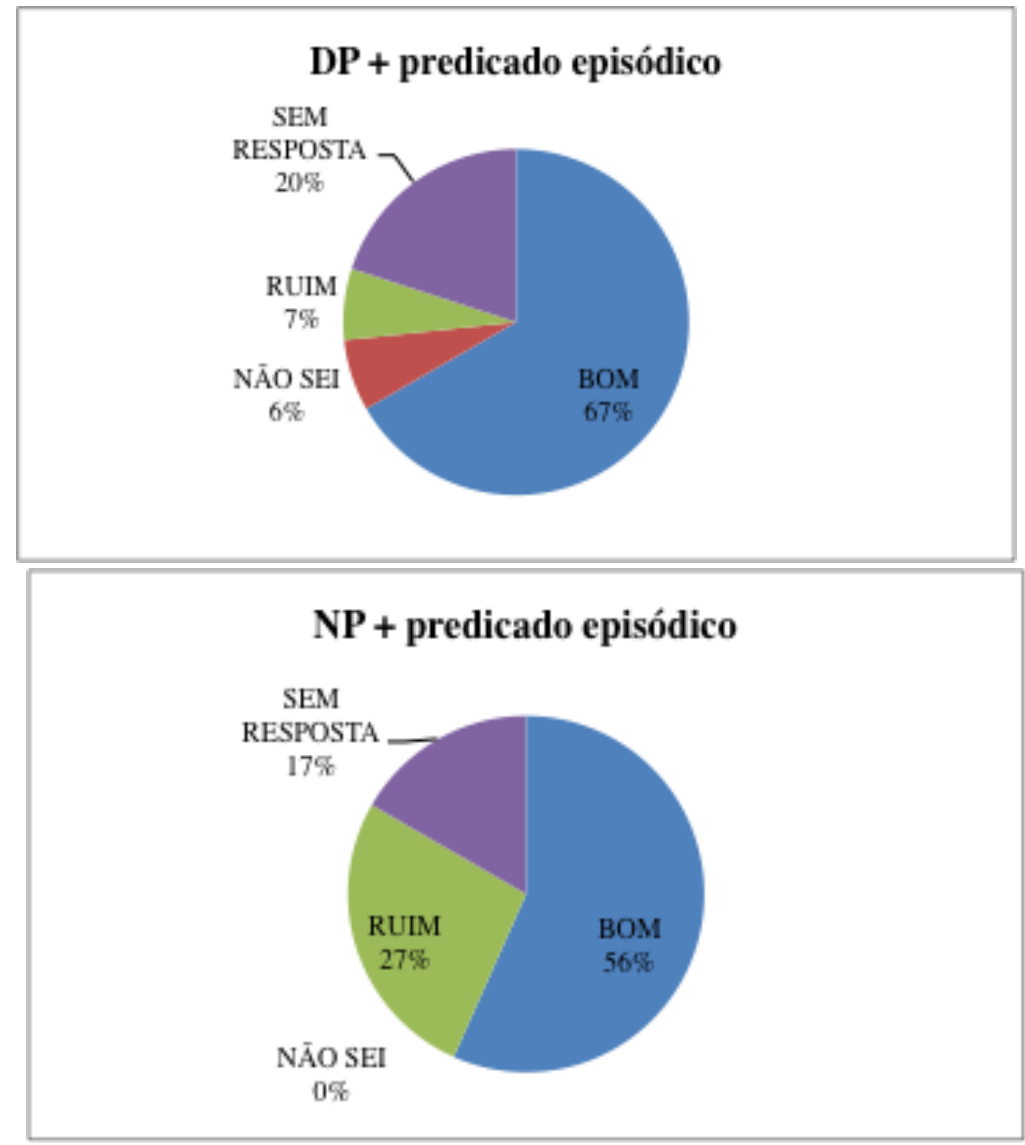

\section{DP + predicado de espécie}

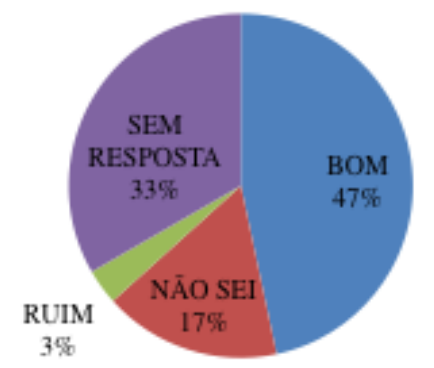




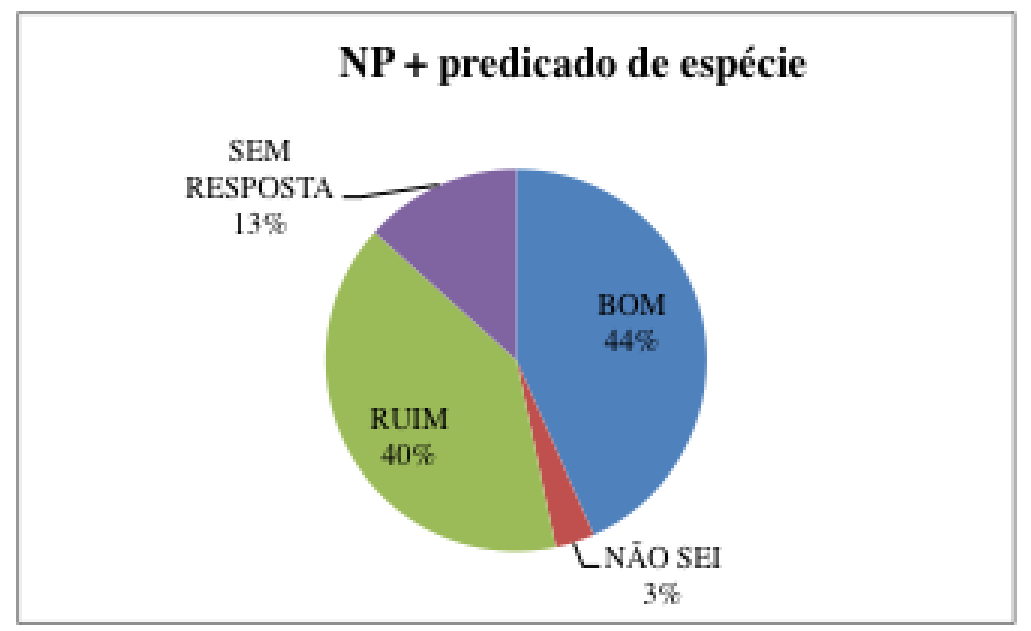

Gráficos 2: Percentual de julgamentos bons, não sei e ruins por condição experimental.

Como pode ser observado nos gráficos, os resultados obtidos na condição DP + predicado de espécie (com apenas 44\% de aceitação como sentenças "boas"), sugerem, no entanto, que os participantes podem estar rejeitando as sentenças por motivos variados. De fato, apenas as sentenças na condição DP + predicado episódico tiveram aceitação claramente acima do nível da chance, embora sem atingir um julgamento positivo categórico ( $67 \%$ de julgamentos "bons"). Possivelmente, o estranhamento provocado pelo conteúdo de alguns dos estímulos em termos pragmáticos e/ou de conhecimento de mundo, pode ter influenciado o julgamento das sentenças (Ex. O João disse que o café chegou no Brasil em 1990). No caso das sentenças na condição DP + predicado de espécie, o D definido parece restringir a leitura "de espécie" atribuída pelo predicador (Ex. O João leu que o dinossauro foi extinto por um cometa), fato que pode ter acarretado o menor número de julgamentos "bons" atribuído a esse tipo de sentença.

\section{4) Considerações finais}

Como discutimos, diferentemente do ocorre em outras línguas românicas (como o francês, o italiano e o espanhol) ou línguas de outra família (como o inglês), no PB o nominal singular nu muito produtivo, tornando esse fenômeno de grande interesse para muitos estudiosos da área. Sendo assim, ao longo da presente pesquisa, vimos que na literatura relativa à caracterização do $\mathrm{SNu}$ singular não há um consenso, mas que é possível identificar diferentes análises para esse tipo de construção. Com o intuito de iniciar nossa investigação sobre esse tópico, lançamos mão da metodologia experimental de pesquisa e conduzimos um experimento piloto. Apesar do tamanho pequeno da nossa amostra, os resultados obtidos até então permitem tecer algumas considerações ainda que parciais e provisórias.

Tomando nossos resultados em conjunto, observamos que apenas as sentenças na condição DP + predicado episódico registraram julgamentos compatíveis com o esperado para estruturas bem aceitas na língua. Nas outras três condições experimentais os resultados, em termos de julgamentos positivos, foram marginalmente acima do nível da chance $(\mathrm{NP}+$ predicado episódico) ou abaixo do nível da chance $(\mathrm{DP}+$ predicado de 
espécie e NP + predicado de espécie). Diante desses resultados, que de fato estão na mesma direção do reportado por Pires de Oliveira, Silva \& Bressane (2010), não é possível afirmar que $\mathrm{SNu}$ singulares sejam bem aceitos pelos falantes de $\mathrm{PB}$ quando combinados com predicados episódicos genéricos e de espécie.

Da mesma maneira, nossos resultados vão ao encontro de resultados encontrados em pesquisas relativas à interpretação dos nominais nus na aquisição da linguagem, os quais sugerem uma possível dificuldade na atribuição de uma leitura genérica a esse tipo de estrutura, já que, apesar da leitura genérica ser atribuída com maior frequência ao nominal nu, crianças com idade inferior a 3 anos não parecem diferenciar o nominal nu plural do singular (Augusto, 2007). Nesse sentido, o nosso resultado relativo ao tempo de reação nas condições com DPs, quando comparadas com as condições com NPs, também é compatível com o registrado com as crianças: sentenças contendo DPs parecem ser processadas mais facilmente tanto por crianças quanto por adultos falantes de PB.

Nesse sentido, ainda será necessária uma análise minuciosa dos estímulos utilizados, bem como a condução de novos experimentos que sigam de forma mais rigorosa os critérios que embasam a metodologia experimental no campo das ciências cognitivas, para que se possam alcançar resultados mais robustos, fundamentais para alimentar a discussão teórica.

\section{5) Referências bibliográficas}

AUGUSTO, Marina R. A. Marcação de número e genericidade: interpretação genérica na aquisição do PB. Porto Alegre: Letras de Hoje, 2007 p. 35-51.

MARIANO, Ruan de Souza. Nonimais Nus, Tópico e Foco: testando a aceitabilidade em sentenças episódicas. Dissertação (Mestrado). Universidade Federal de Santa Catarina. Florianópolis, 2011.

MEZARI, Meiry Peruchi, Singular Nu: comparando teorias. Trabalho de Conclusão de Curso (Bacharelado em Letras). Universidade Federal de Santa Catarina, 2011.

MÜLLER, Ana Lúcia. Sentenças genericamente quantificadas e expressões de referência a espécies no português brasileiro. Cadernos de Estudos Lingüísticos (UNICAMP) 39: 141-158, 2000.

A expressão da genericidade nas línguas naturais. In: MÜLLER, Ana; NEGRÃO, Esmeralda Vailati; FOLTRAN, Maria José (Orgs.). Semântica Formal. São Paulo: Contexto, 2003. p.153-173.

PIRES DE OLIVEIRA, R. SILVA, J. C. \& BRESSANE, M. R. S.. O singular nu denota espécie: uma investigação empírica. Delta 26(1): 115-139, 2010. 
PIRES DE OLIVEIRA, R. Os vários modos de ser nu: uma introdução. In: PIRES DE OLIVEIRA, R. \& PERUCHI MEZARI, M. (Org.). Nominais nus: um olhar através das línguas. SP: Mercado das Letras, 2012.

PIRES DE OLIVEIRA, R. \& Rothstein, S. (2011) Bare singular noun phrases are mass in Brazilian Portuguese. Lingua, 121: 2153-2175. 